\title{
Menghadapi Era Abad 21: Tantangan Guru Pendidikan Anak Usia Dini di Kabupaten Bone Bolango
}

\author{
Rusmin Husain $^{1}{ }^{凶}$, Anton Kaharu $^{2}$ \\ Pendidikan Guru Sekolah Dasar, Universitas Negeri Gorontalo(1) \\ Teknik Sipil, Universitas Negeri Gorontalo(2) \\ DOI: $\underline{10.31004 / \text { obsesi.v5i1.527 }}$
}

\begin{abstract}
Abstrak
Tujuan penelitian ini adalah guru pendidikan anak usia dini perlu memiliki bekal dalam menghadapi abad 21 untuk menjadi guru yang profesional. Penelitian ini dilakukan pada guru pendidikan anak usia dini di kabupaten Bone Bolango, Gorontalo, dengan jenis penelitian deskriptif kualitatif. Teknik pengumpulan data yang digunakan yaitu wawancara, observasi dan dokumentasi. Hasil penelitian menunjukkan bahwa pada kegiatan workshop, guru pendidikan anak usia dini di Tapa Bonebolago yaitu mampu membuat RPP dan silabus pembelajaran sesuai dengan pendidikan Nasional yang dikemas melalui K-13 dan disesuaikan dengan kondisi daerah yang diakses melalui jaringan IT, sehingga informasi mudah diakses oleh guru. Sangat penting bagi guru untuk mengenal dan mengintegrasikan teknologi dalam pembelajaran, sehingga guru memiliki pengetahuan dan kompetensi dalam mengajar dan melatih keterampilan abad ke-21 kepada anak.
\end{abstract}

Kata Kunci: abad-21; pendidikan anak usia dini; anak usia dini.

\begin{abstract}
The purpose of this study is that early childhood education teachers need to have provisions in facing the 21st century to become professional teachers. This research was conducted on early childhood education teachers in Bone Bolango district, Gorontalo, with a descriptive qualitative research type. Data collection techniques used were interviews, observation and documentation. The results showed that in the workshop activities, early childhood education teachers in Tapa Bonebolago were able to make lesson plans and learning syllabi in accordance with the national education that was packaged through K-13 and adapted to local conditions accessed through the IT network, so information was easily accessed by teachers . It is very important for teachers to recognize and integrate technology in learning, so that teachers have the knowledge and competence in teaching and practicing 21st century skills to children.
\end{abstract}

Keywords: 21st century; early childhood education; early childhood.

Copyright (c) 2020 Rusmin Husain, Anton Kaharu

$\triangle$ Corresponding author :

Email Address : rusmin.husain@ung.ac.id (Gorontalo, Indonesia)

Received 4 April 2020, Accepted 1 May 2020, Published 8 May 2020 


\section{PENDAHULUAN}

Menghadapi era global yang diperkirakan ketat dengan persaingan disegala bidang kehidupan, khususnya dunia kerja yang semakin kompetitif, tidak ada alternatif lain selain berupaya meningkatkan kualitas sumber daya manusia melalui upaya peningkatan mutu pendidikan di setiap jenjang pendidikan. Guna tercapainya tujuan dimaksud selain harus didukung pengembangan program dan kurikulum serta berbagai macam model penyelenggaraan pembelajaran anak yang telah diamanatkan oleh Undang-undang No.20 tahun 2003 tentang sistem pendidikan nasional serta dipengaruhi perubahan perkembangan yang semakin cepat, maka peningkatan mutu atau kualitas pendidikan sangat ditentukan oleh guru yang profesional atau profesionalisme guru merupakan pilar utama dalam peningkatan mutu pendidikan (Roza et al., 2020).

Rice dan Bishprick (dalam Ibrahim 2003) menyebutkan bahwa guru profesional adalah guru yang mampu mengelola dirinya sendiri dalam melaksanakan tugas sehari-hari. Profesionalisasi guru oleh kedua pasangan penulis tersebut dipandang sebagai salah satu proses yang bergerak dari ketidaktahuan (ignorance) menjadi tahu, dari ketidakmatangan (immaturity) menjadi matang, dari diarahkan oleh orang lain menjadi mengarahkan diri sendiri. Peningkatan mutu pendidikan berbasis sekolah (MPMBS) mempersyaratkan adanya guru-guru yang memiliki pengetahuan luas, kematangan, dan mampu menggerakkan dirinya sendiri dalam rangka meningkatkan mutu pendidikan di sekolah. Memang benar apabila seorang guru yang mampu mengelola diri sendiri bisa dikatakan profesional, karena apabila ia telah mampu mengelola dirinya sendiri maka ia juga akan mampu mengelola orang lain. Namun apabila seorang guru saja tidak mampu mengelola dirinya sendiri, maka bagaimana bisa ia mengelola anak didiknya.

Memasuki abad 21 profesionalisme guru menjadi syarat utama dalam upaya meningkatkan mutu pendidikan. Abad ke-21 adalah abad yang sangat berbeda dengan abad-abad sebelumnya. Perkembangan ilmu pengetahuan yang luar biasa disegala bidang. Pada abad ini, terutama bidang Information and Communication Technology (ICT) yang serba canggih (sophisticated), membuat dunia ini semakin sempit (Garba et al., 2015; Surya, 2017). Karena kecanggihan teknologi ICT ini beragam informasi dari berbagai sudut dunia mampu diakses dengan instan dan cepat oleh siapapun dan dari manapun, komunikasi antar personal dapat dilakukan dengan mudah, murah kapan saja dan di mana saja (B Boholano, 2017). Tidak hanya berkembangnya bidang ICT, pada abad ke-21 guru dituntut untuk profesional dalam dunia pendidikan khususnya perkembangan anak dan aspek kunci dari lingkungan kelas abad ke-21 yaitu keterlibatan anak, penggunaan strategi pembelajaran yang efektif serta factor emosional guru dalam mendukung perkembangan anak (Kim et al., 2019; Seidman et al., 2018).

Nessipbayeva (2019) kompetensi mengajar guru abad ke-21 yaitu: 1) guru menunjukkan kepemimpinan, guru menunjukkan kepemimpinan di sekolah, guru memimpin profesi guru, guru mengadvokasi sekolah dengan anak. 2) guru membangun lingkungan yang penuh hormat untuk anak yang beragam, guru merangkul keragaman dikomunitas sekolah, guru memperlakukan anak sebagai individu, guru mengadaptasi pengajaran untuk kepentingan anak yang berkebutuhan khusus, guru bekerja secara kolaboratif dengan orang tua anak. 3) guru tahu materi yang mereka ajarkan, guru memahami materi yang sesuai dengan bidang guru, guru menunjukkan bahwa ia memahami materi, guru membuat instruksi yang relevan dengan anak. 4) guru memfasilitasi pembelajaran untuk anak, merencanakan instruksi yang sesuai dengan anak, para guru menunjukkan kesadaran akan meningkatkan potensi teknologi, guru membatu anak tumbuh sebagai individu yang berpikir, guru membantu anak untuk bekerja tim, memberikan motivasi pada anak, guru membuat evaluasi. Hal ini berlaku pada guru jenjang apapun, salah satunya yaitu guru pendidikan anak usia dini. 
Guru pendidikan anak usia dini sangat berperan penting dalam pertumbuhan dan perkembangan anak, karena itu menjadi seorang guru pendidikan anak usia dini hendaknya memiliki skill yang baik dalam memberikan stimulasi pada anak, membimbing, dan mengarahkan anak dengan sebaik-baiknya. Selain itu peran guru ialah senantiasa untuk meningkatkan kemampuan professional dalam menjalakan tugas dan kewajiban dalam meningkatkan kualitas sumber daya manusia khusunya anak usia dini (Muhson, 2004; Tanang \& Abu, 2014). Guru PAUD inilah yang akan mewariskan kebudayaan, sebagai komponen yang menentukan tingginya kualitas sumber daya manusia, sebagai agen penggerak untuk meningkatkan taraf hidup masyarakat menuju yang lebih baik. Guru yang mempunyai kemampuan tersebut yang dikatakan sebagai guru PAUD profesional pada abad 21.

Guru pendidikan anak usia dini perlu melaksanakan tugas dan tantangan dalam meningkatkan kualitas pendidikan pada abad 21, dengan meningkatkan kualitas tersebut maka tujuan menumbuh kembangkan kercerdasan anak akan berjalan dengan optimal (Zubaidi, 2020). Tantangan guru pendidikan anak usia dini yang profesional pada abad 21 ialah mampu merefleksikan praktik yang dilakukan di sekolah, mampu merefleksikan pekerjaan pedagogis, guru memiliki wawasan yang luas, menganalisis tantangan menjadi guru yang professional, mampu bersosialisasi dengan anak, mampu mengelolah menejemen, mampu memimpin staf (Aasen \& Sadownik, 2019). Sedangkan Peterson et al., (2016) tantangan menjadi guru professional pada pendidikan anak usia dini ialah keterlibatan guru, mampu berinteraksi, mampu membuat perencanaan, mampu membuat evaluasi perkembangan anak, menggunakan stategi pembelajaran yang tepat dan efektif, termotivasi untuk pengembangkan profesi, menciptakan lingkungan pertumbuhan serta perkembangan anak.

Selain itu, Tantangan guru PAUD pada era abad 21 terdapat lima dimensi diantaranya sebagai berikut: keterampilan administrasi, keterampilan technopedagogic, keterampilan konfirmasi, ketrampilan belajar yang fleksibel dan keterampilan produktif (Göksün \& Kurt, 2017). Darling (dalam Mappapoleonro, 2019) guru abad 21 dituntut untuk melaksanakan dan mempu membangung hubungan efektif dengan anak, orang tua dan masyarakat, guru mampu mengunakan teknologi dalam meningkatkan mutu pengejaran, serta melakukan refleksi dan perbaikan praktek pembelajaran secara terus-menerus. Terdapat empat fase proses adobsi dan adaptasi guru dalam pembelajaran abad 21 yaitu dabbling, old things in old ways, old things in new ways, doing new things in new ways (Smaldino dalam Prayogi et al., 2019).

Berdasarkan di lapangan dilakukan wancara bahwa masih terdapat guru yang belum bias merubah pola pikir sehingga pembelajaran venderung lebih membosankan, kemudian guru masih mengangap dirinya sebagai satu-satunya sumber ilmu pengetahuan. Hal ini senada dengan beberapa hasil penelitian yang sudah dilakukan bahwa beberapa pendidik PAUD belum memperlihatkan tingkat keterpanggilan jiwa seperti guru PAUD belum menjalankan tugas pokok yang telah ditentukan, belum melibatkan dan terlibat dalam aktivitas kegiatan secara penuh, belum memberikan pelayanan yang sesuai dengan anak usia dini, kurang memilki kesadaran dalam menjalankan peran sebagai penyelenggara perlindungan anak, guru terkesan cuek, guru kurang kreatif dan inovatif (Ayuni \& Setiawati, 2019; Janah et al., 2019; Roza et al., 2020; Zubaidi, 2020).

Selain itu, kesejahteraan guru di Indonesia yang relatif rendah kalau dibanding dengan kesejahteraan kaum profesional lain diperkirakan telah menjadi kendala paling mendasar dalam upaya riil peningkatan profesionalisme guru. Relatif rendahnya kesejahteraan guru diperkirakan telah berpengaruh pada aktivitas guru baik di dalam kelas, di lingkungan sekolah maupun di lingkungan masyarakat. Relatif rendahnya kesejahteraan guru telah menjadikan aktivitasnya kurang optimal dan produktif. 
Berdasarkan Permasalahan di atas, penting untuk diteliti bagaimana Tantangan Guru Pendidikan Anak Usia Dini dalam Menghadapi Era Abad 21 Di Kabupaten Bone Bolango Provinsi Gorontalo. Tujuan dilakukan penelitian ini adalah guru pendidikan anak usia dini perlu memiliki bekal dalam menghadapi abad 21 untuk menjadi guru yang profesional.

Keterbaruan dari penelitian ini adalah mempersiapkan tantangan guru PAUD dalam menghadapi era abad 21 di Kabupaten Bone Bolango Provinsi Gorontalo. Penelitian Surya (2017) berfokus dengan pendidikan karakter abad 21 pada anak usia dini dengan hasil penelitian penggunaan model pembelajaran pendidikan karakter abad 21 merupakan proses pemberdayaan potensi anak dengan proses humanisasi, pembudayaan, model penalaran moral, analisis dan project citizen. Penelitian Anagün (2018) menguji hubungan anatara persepsi guru pada sekolah dasar tentang keahlian guru dalam hal keterampilan abad ke-21 dan persepsi kaitannya dengan mengelola lingkungan belajar konstruktivis dengan menggunakan permodelan persaman structural. Göksün \& Kurt (2017) penelitian yang dilakukan menguji hipotesis guru mengajarkan cara belajar dalam lingkup keterampilan anak abad ke-21 dan keterampilan guru abad ke-21. Penelitian Mappapoleonro (2019) tujuan pada penelitian adalah untuk meningkatkan profesionalisme guru PAUD dalam mengembangkan pembelajaran abad 21.

\section{METODOLOGI}

Metode yang yang digunakan adalah metode survey, jenis penelitian deskriptif kualitatif, yang hasil penelitian penelitian dinarasikan secara detail melalui kegiatan workshop yang dilaksanakan di PAUD Kabupaten Bone bolango. Tehnik pengumpulan data pada penelitian ini yaitu Observasi, wawancara dan Dokumentasi. Analisi data yang digunakan dalam penelitian ini reduksi data, penyajian data, dan penarikan kesimpulan (Miles \& Huberman, 2005). Berikut ini tahap-tahap penelitian yang dilakukan peneliti.

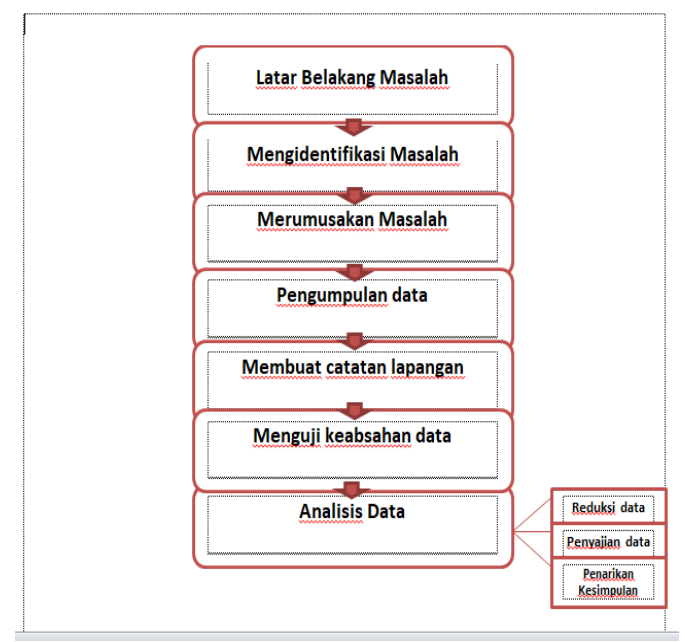

Gambar 1. Tahapan Penelitian (Anggito \& Setiawan, 2018)

\section{HASIL DAN PEMBAHASAN}

Berdasarkan hasil penelitian dengan permasalahan kompleks dari Guru PAUD yang telah diuraikan sebelumnya dalam latar belakang masalah, maka solusi menghadapi era abad 21 sebagai tantang besar bagi guru untuk menjadi lebih profesional lagi. Solusinya adalah pelaksaan kegiatan pendampingan penguatan profesionalisasi guru PAUD melalui Mou kerjasama dengan pihak sekolah terutama PAUD Nurul Hikmah Tapa Kabupaten Bone bolango, melalui kegiatan seminar dan workshop, diberikan penguatan dan pemahaman serta trik tentang bagaimana menjadi Guru PAUD dalam menghadapi era abad 21, yang kompleks menguasai teknologi. 
Pada workshop yang dilakukan pemateri pertama menyampikan tentang “ Tantangan Guru PAUD Abad 21" materi yang disampaikan berupa Pengertian Abad 21, Kompetensi Guru PAUD Abad 21, Orientasi Guru PAUD Abad 21, Orentasi Pembelajaran PAUD Abad 21. Sedangkan materi yang disampaikan "Teknis Operasi System Pembelajaran IT" yaitu Pengertian dan Manfaat Pembelajaran IT, Problematika Guru PAUD dalam Menguasai Pembelajaran Berbasis IT, Impelementasi Penggunaan IT dalam Pembelajaran. Berikut ini gambar dari kegiatan workshop yang dilakukan oleh peneliti.

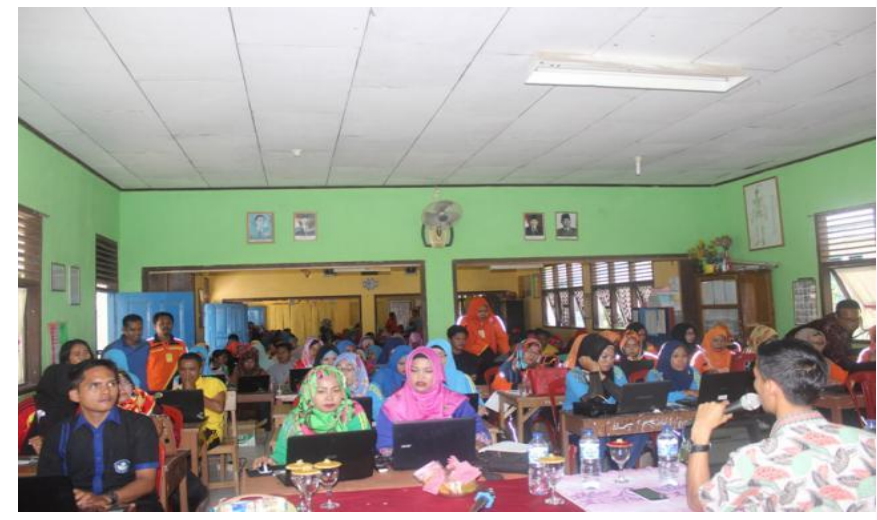

Gambar 2. Penyampain Materi

(Tantangan Guru Paud Abad 21 dan Teknis Operasi System Pembelajaran IT

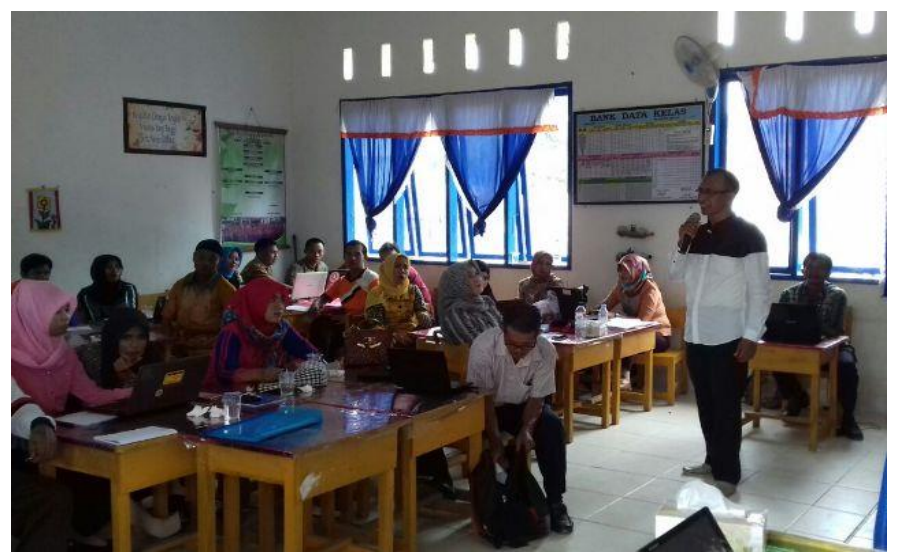

\section{Gambar 3. Salah Satu Peserta Workshop Tampil Di Depan}

Setelah pemateri dua menyampaikan materi tentang Teknis Operasi Sytem Pembelajaran IT, selanjutnya pemateri melakukan "Akses Luaran Kegiatan" yang dibagi beberapa kelompok pada guru PAUD. Tujuan dibaginya kelompok dalam workshop ini adalah agar mempermudah guru yang masih kesulitan dalam penggunaan teknologi dan dapat belajar atau diarahkan dengan guru yang sudah paham penggunaannya. Masingmasing satu kelompok terdiri dari 8 orang guru PAUD, kemudian dalam satu kelompok diminta untuk membawa laptop minimal 2 laptop. "Akses Luaran Kegiatan" berupa kegiatan Akses internet guru PAUD dalam pelatihan mengunduh file sesuai dengan lingkungan, religi dan sosiolisasi. Materi dapat diakses dan diunduh, serta di operasikan melalui digital, untuk mengantisipasi situasi pembelajaran yang sulit, bertatap muka dengan anak-anak dan orang tuanya.

Pada kegiatan ini guru mengunduh materi tentang pembuatan RPP dan Silabus untuk kegiatan pembelajaran di PAUD. Setelah guru mengunduh file yang berisi contoh pembuatan RPP dan Silabus, selanjutnya guru diminta untuk membuat RPP dengan menggunakan laptop tanpa menggunakan buku, dengan tujuan mempermudah guru dalam pembuatan Program Tahunan, Program Semester, RPPM, dan RPPH. Tehnik dan sistem 
Pembelajaran ini harus di dukung oleh akses internet yang baik dan cepat serta keterampilan guru PAUD yang mampu menghadapi tantangan dan percepatan di bidang ilmu pengetahuan dan teknologi. Karena tehnik dan sistem komunikasi seperti mudahnya akses internet menjadi salah satu ciri abad 21. Dunia seakan-akan menjadi kecil dan berada dalam genggaman, apa yang terjadi di ujung dunia sana akan dengan mudah diketahui oleh orang manapun dan dalam waktu yang bersamaan. Berbagai teknologi canggih yang pada intinya untuk mempermudah segala macam urusan manusia ditemukan, dikembangkan, dibuat dan dipakai oleh banyak orang dengan biaya yang sangat terjangkau. Berikut ini gambar tahap dari penelitian yang dilakukan.

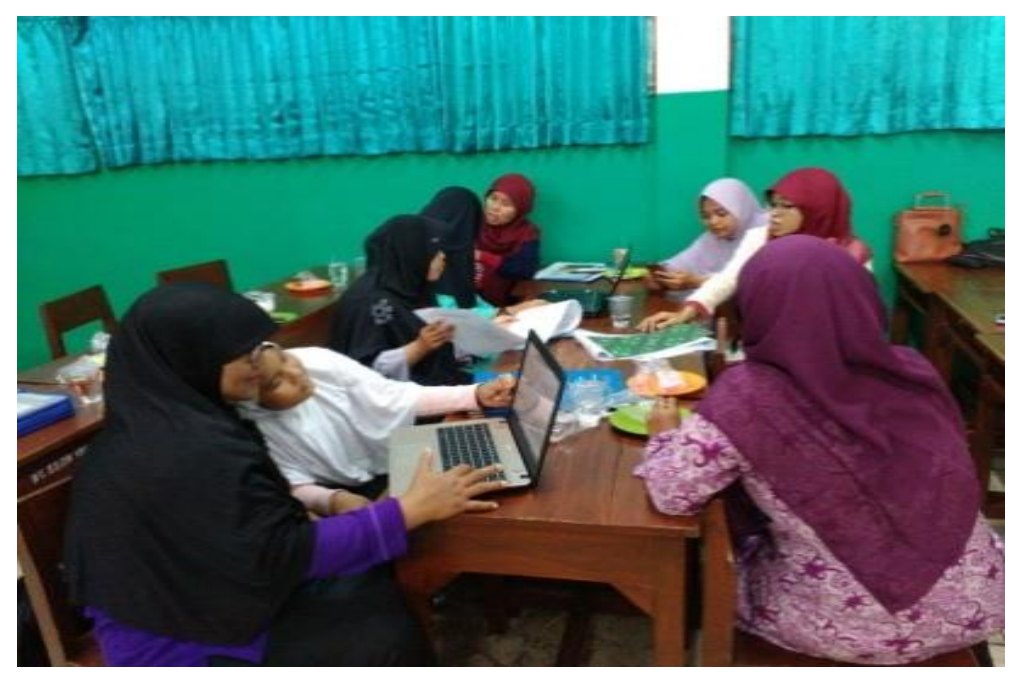

Gambar 3. Pembagian Kelompok untuk Mengakses Materi dan File

Setelah mengikuti workshop peneliti mewawancarai beberapa sumber tentang pentingnya mempersiapkan diri dalam menghadapi abad 21. "setelah saya mengikuti workshop ini, saya menyadari bahwa setiap guru PAUD harus mempunyai bekal dalam menghadapi abad 21, terutama kompetensi-kompetensi yang diperlukan pada abad 21. Dengan adanya workshop ini saya mendapatkan ilmu baru dan sangat bermanfaat sekali, insyallah nanti bisa kami terapkan di sekolah" (Narasumber D.S). Kemudian terdapat respon narasumber (W.P) "setelah mengikuti workshop ini saya perlu membekali diri saya untuk menghadapi abad 21, agar saya tidak gaptek dan bisa saya gunakan dalam proses pembelajaran di kelas nantinya" Berdasarkan hasil wawanacara dari beberapa guru PAUD bahwa setelah dilakukan workshop guru merasa pentingnya mempunyai bekal dan persiapan dalam menghadapi era abad 21, dengan adanya bekal guru tidak ketinggalan zaman ketika teknologi sudah perkembang pesat.

Kemudian peneliti melakukan wawancara mengenai tantangan penggunaan teknologi dalam pembelajaran. Masih terdapat guru yang masih kesulitan dalam penggunaan teknologi, seperti pernyataan dari narasumber R.F.P "memang kami diajarkan untuk mengakses file seperti RPP dan silabus, kemudian kami diminta untuk menyusun program dengan menggunakan laptop, tapi saya masih sedikit kesulitan dalam penggunaannya tetapi saya mampu membuat RPP dan Silabus. Dengan demikian setidaknya kami bisa belajar dan tertantang untuk menjadi guru yang bisa menggunakan teknologi, apa lagi sekarang anak-anak sudah mulai mengenal teknologi". Sedangkan guru memberikan pernyataan dengan adanya workshop yang dilakukan penekli dapat memberikan ilmu baru untuk pembelajaran, "Alhamdulillah setidaknya saya mengupgred ilmu baru saya dalam menyusun atau merancang pembelajaran di sekolah" (Narasumber S.O.S). 
Kemudian Permasalahan akses kegiatan workshop untuk Guru PAUD dalam mengantisipasi zaman pada abad 21 ini, juga secara nyata membawa dampak yang tidak sedikit. Baik dampak terhadap fisik maupun dampak terhadap cara kerja, cara mendidik dan cara menerapkan psikologis sosial untuk anak didik. Sebagaimana dampak tersebut adalah cita-cita setiap lembaga dan bangsa untuk mewujudkan kesejahteraan dan kebahagiaan bagi seluruh rakyatnya, serta hidup sejajar dan terhormati kalangan bangsa-bangsa lain. Akses penguatan skill guru PAUD untuk menghadapi masalah global dalam abad 21 ini. Semua ini dapat dan harus dicapai dengan kemauan dan kemampuan sendiri, yang hanya dapat ditumbuh-kembangkan melalui pendidikan yang harus diikuti oleh seluruh anak bangsa. Kata kunci dalam pendidikan ini adalah kemandirian. Dengan demikian, tujuan teknik dan sistem pembelajaran profesionalisasi guru PAUD searah dengan sistem pendidikan nasional, sehingganya yang menjadi target luaran dari kegiatan workshop untuk Guru Paud di Tapa Bonebolango yakni guru PAUD dapat membuat RPP dan silabus pembelajaran yang sesuai dengan sistem pendidkan Nasional yg dikemas melalui K13 dan di sesuaikan dengan kondisi daerah, yang diakses melalui jaringan IT, agar informasinya dapat di akses oleh guru PAUD di Tapa Kabupaten Bone Bolango.

Dunia di abad ke-21 berkembang sangat pesat karena berkembangnya dunia Teknologi Informasi dan Komunikasi (TIK) dan kemajuan teknologi di seluruh penjuru dunia. Pada abad 21 melibatkan teknologi yang mampu mengubah ekonomi, system social politik dunia, dan memberikan tekanan besar para pemimpin. Perkembangan dan kemajuan ini berpengaruh juga pada scenario pendidikan. Dimana anak abad 21 dikenal juga sebagai pendidik asli digital atau millennium belajar di ruang kelas berbeda dengan anak dari generasi sebelumnya, karena anak sekarang dikelilingi oleh teknologi (Lemley et al., 2014). Oleh karena itu guru tidak bias lagi hanya bergantung pada metode konfensional. Guru harus menyadari perkembangan teknolgi saat ini, maka kebutuhan untuk berubah cara mengajar di kelas abad ke-21. Keterampilan abad ke-21 terjadi dalam pendidikan hari ini, agar anak memiliki kesiapan untuk masa depannya. Sangat penting bagi guru untuk mengenal dan mengintegrasikan teknologi dalam pembelajaran, sehingga guru harus memiliki pengetahuan dan kompetensi dalam mengajar dan melatih keterampilan abad ke21 kepada anak (Anagün, 2018).

\section{SIMPULAN}

Menghadapi tantangan abad 21, setiap guru hendaknya memiliki kemampuan dan profesionalisme yang tinggi. Tantangan yang dihadapi tidak lagi berkisar pada kemampuan akademik anak, tetapi lebih pada pendidikan intelektual, emosional, moral dan akhlak siswa. Setiap guru PAUD harus memiliki kompetensi sebagaimana yang telah diamanatkan di dalam Undang-Undang serta tuntutan zaman. Hal ini dapat menentukan kualitas penyiapan sumberdaya manusia menghadapi abad 21.

\section{UCAPAN TERIMAKASIH}

Ucapan terima kasih peneliti kepada pihak-pihak terkait, terutama guru pendidikan anak usia dini di Kabupaten Bone Bolango Provinsi Gorontalo.

\section{DAFTAR PUSTAKA}

Aasen, W., \& Sadownik, A. R. (2019). Does the New Kindergarten Teacher Education Program in Norway Provide Good Conditions for Professional Kindergarten Teachers? 7, 1-7. https://doi.org/10.13189/ujer.2019.071301

Anagün, Ş. S. (2018). Teachers' perceptions about the relationship between 21st century skills and managing constructivist learning environments. International Journal of Instruction, 11(4), 825-840. https:// doi.org/10.12973/iji.2018.11452a

Anggito, A., \& Setiawan, J. (2018). Motodologi Penelitian Kualitatif. CV Jejak. 
Ayuni, D., \& Setiawati, F. A. (2019). “Kebun Buah” Learning Media for Early Childhood Counting Ability Despa. Jurnal Obsesi : Jurnal Pendidikan Anak Usia Dini, 3(1), 1-9. https:// doi.org/10.31004/obsesi.v3i1.128

B Boholano, H. (2017). Smart Social Networking: 21st Century Teaching andLearning Skills. Research in Pedagogy, 7(1), 21-29. https://doi.org/10.17810/2015.45

Garba, S. A., Byabazaire, Y., \& Busthami, A. H. (2015). Toward the use of 21st century teaching-learning approaches: The trend of development in Malaysian schools within the context of Asia Pacific. International Journal of Emerging Technologies in Learning, 10(4), 72-79. https:// doi.org/10.3991/ijet.v10i4.4717

Göksün, D. O., \& Kurt, A. A. (2017). The relationship between pre-service teachers' use of 21st century learner skills and 21st century teacher skills. Egitim ve Bilim, 42(190), 107130. https://doi.org/10.15390/EB.2017.7089

Ibrahim, B. (2003). Peningkatan Profesionalisme Guru Sekolah Dasar. Bumi Aksara.

Janah, R., Akbar, Z., \& Yetti, E. (2019). Pengaruh Iklim Organisasi terhadap Kinerja Guru PAUD di Kota Depok. Jurnal Obsesi: Jurnal Pendidikan Anak Usia Dini, 4(1), 234. https:// doi.org/10.31004/obsesi.v4i1.236

Kim, S., Raza, M., \& Seidman, E. (2019). Improving 21st-century teaching skills: The key to effective 21st-century learners. Research in Comparative and International Education, 14(1), 99-117. https://doi.org/10.1177/1745499919829214

Lemley, J. B., Schumacher, G., \& Vesey, W. (2014). What Learning Environments Best Address 21st-Century Students' Perceived Needs at the Secondary Level of Instruction? NASSP Bulletin, 98(2), 101-125. https:/ / doi.org/10.1177/0192636514528748

Mappapoleonro, A. M. (2019). Profesionalisme Guru PAUD Abad 21 dalam Mengembangkan Pembelajaran Kreativitas Anak Usia Dini. 1-8.

Miles, M., \& Huberman, M. (2005). No Qualitative Data Analysis (Terjemah). UI Press.

Muhson, A. (2004). Meningkatkan Profesionalisme Guru : Sebuah Harapan. Jurnal Ekonomi \& Pendidikan, 2(1). https://doi.org/10.21831/jep.v1i2.665

Nessipbayeva, O. (2019). The competencies of the modern teacher. International Perspectives on Education, 148-154. http:/ / bit.ly/2fRwNoY

Peterson, T., Veisson, M., Hujala, E., Härkönen, U., Johansson, I., Bakosi, E. K., Peterson, T., Veisson, M., Hujala, E., \& Härkönen, U. (2016). Professionalism of preschool teachers in Estonia ,. European Eraly Childhood Education Research Journal, 24(1), 136-156. https:/ / doi.org/10.1080/1350293X.2015.1120529

Prayogi, R. D., Estetika, R., Pascasarjana, S., \& Surakarta, U. M. (2019). Kecakapan Abad 21 : Kompetensi Digital Pendidik Masa. 14(2), 144-151.

Roza, D., Nurhafzah, \& Yaswinda. (2020). Urgensi Profesionalisme Guru Pendidikan Anak Usia Dini dalam Penyelenggaraan Perlindungan Anak. Jurnal Obsesi: Jurnal Pendidikan Anak Usia Dini, 4(1), 267-273. https://doi.org/10.31004/obsesi.v4i1.325

Seidman, E., Kim, S., Raza, M., Ishihara, M., \& Halpin, P. F. (2018). Assessment of pedagogical practices and processes in low and middle income countries: Findings from secondary school classrooms in Uganda. Teaching and Teacher Education, 71, 283296. https:// doi.org/10.1016/j.tate.2017.12.017

Surya, Y. F. (2017). Penggunaan Model dan Pendekatan Pembelajaran Pendidikan Karakter Abad 21 pada Anak Usia Dini. Jurnal Obsesi : Journal of Early Childhood Education, 1(1), 52. https://doi.org/10.31004/obsesi.v1i1.48

Tanang, H., \& Abu, B. (2014). Teacher Professionalism and Professional Development Practices in South Sulawesi , Indonesia. Journal of Curriculum and Teaching, 3(2), 25-42. https:// doi.org/10.5430/jct.v3n2p25

Zubaidi, M. (2020). Jurnal Obsesi: Jurnal Pendidikan Anak Usia Dini Profesionalisme Guru dan Efektivitas Pembelajaran pada Pendidikan Anak Usia Dini Abstrak. 4(2), 1060-1067. https:// doi.org/10.31004/obsesi.v4i2.505 